\title{
Vocabulary skills are well developed in university students with dyslexia: Evidence from multiple case studies
}

\author{
Eddy Cavalli ${ }^{\mathrm{a}, *}$, Séverine Casalis ${ }^{\mathrm{b}}$, Abdessadek El Ahmadi $^{\mathrm{c}}$, Mélody Zira $^{\mathrm{a}}$, \\ Florence Poracchia-George ${ }^{\mathrm{d}}$, Pascale Colé $\mathrm{e}^{\mathrm{a}, *}$ \\ ${ }^{a}$ Aix-Marseille université, Laboratoire de Psychologie Cognitive (UMR 7290) and CNRS, France \\ ${ }^{\mathrm{b}}$ Université Charles-de-Gaulle Lille III, Laboratoire SCALab (UMR 9193) and CNRS, France \\ ${ }^{\mathrm{c}}$ Aix-Marseille université, Laboratoire de Neurosciences Intégratives et Adaptatives (UMR 7260) and CNRS, France \\ ${ }^{\mathrm{d}}$ Hôpital SALVATOR service IDEC/CERTA, France
}

A R T I C L E I N F O

\section{Article history:}

Received 21 July 2015

Received in revised form 6 November 2015

Accepted 8 January 2016

Available online

\section{Keywords:}

University students with dyslexia

Vocabulary breadth

Vocabulary depth

Rasch model

Multiple-case studies

\begin{abstract}
A B S T R A C T
Most studies in adults with developmental dyslexia have focused on identifying the deficits responsible for their persistent reading difficulties, but little is known on how these readers manage the intensive exposure to written language required to obtain a university degree. The main objective of this study was to identify certain skills, and specifically vocabulary skills, that French university students with dyslexia have developed and that may contribute to their literacy skills. We tested 20 university students with dyslexia and 20 normal readers (matched on chronological age, gender, nonverbal IQ and level of education) in reading, phonological, vocabulary breadth (number of known words), and vocabulary depth (accuracy and precision) tasks. In comparing vocabulary measures, we used both Rasch model and single case study methodologies. Results on reading and phonological tasks confirmed the persistence of deficits in written word recognition and phonological skills. However, using the Rasch model we found that the two groups performed at the same level in the vocabulary breadth task, whereas dyslexics systematically outperformed their chronological age controls in the vocabulary depth task. These results are supplemented by multiple case studies. The vocabulary skills of French university students with dyslexia are well developed. Possible interpretations of these results are discussed.
\end{abstract}

(c) 2016 Elsevier Ltd. All rights reserved.

What does this paper add?

This study looked at strengths of university students with dyslexia, an innovative approach in comparison to the majority of studies, which describe only the deficits of these readers. We investigated whether the development of one oral language skill, namely vocabulary skill, is preserved in university students with dyslexia. We then examined vocabulary breadth and depth using both quantitative (using the Rasch model) and case study methodologies. The demonstration that vocabulary skills are potential compensatory reading skills in this population is its novel contribution.

\footnotetext{
* Corresponding authors at: Laboratoire de Psychologie Cognitive, Aix-Marseille Université, 3, Place Victor Hugo, Bat. 9, Case D, 13331 Marseille Cedex 3, France.

E-mail addresses: eddy.cavalli@univ-amu.fr (E. Cavalli), severine.casalis@univ-lille3.fr (S. Casalis), Abdessadek.el-ahmadi@univ-amu.fr (A.E. Ahmadi), melody.zira@gmail.com (M. Zira), florence.poracchia@ap-hm.fr (F. Poracchia-George), pascale.cole@univ-amu.fr (P. Colé).
} 


\section{Introduction}

The majority of studies conducted with university students with dyslexia have attempted to identify the deficits responsible for their persistent reading difficulties, while only a few have looked at these readers' strengths (Leong, 1999; as well as Elbro \& Arnbak, 1996, for adolescents with dyslexia). And yet such analyses could shed considerable light on the question of how these readers manage to read successfully. According to Gough and Tunmer's (1986) "simple" view of reading, reading comprehension skills depend on both written word recognition and oral comprehension. Research on these readers has shown persistent deficits in written word recognition (see the meta-analysis of Swanson \& Hsieh, 2009) and in several forms of phonological processing that are involved in reading, such as phonological awareness, phonological short-term memory, and rapid access to phonological word representations. Neuroimaging studies have confirmed the presence of phonological deficits (for a review see Richlan, Kronbichler, \& Wimmer, 2011) and results suggest that this cognitive deficit arises from congenital dysfunction in certain cortical areas involved in phonology and reading. Studies demonstrating the impairment of both written word recognition and phonological skills in university students with dyslexia have given no indication on how these adults manage the intensive exposure to written language required to obtain a university degree.

Importantly, it has often been argued that children with developmental dyslexia are able to compensate for their reading problems (Bruck, 1992; Snowling, 2000). The model of Bishop and Snowling (2004) is of particular interest: they propose that differences in the balance between phonological and nonphonological skills (e.g., semantics, reading comprehension, ability to use linguistic context. .) may account for different profiles of reading and spelling impairments. For instance, dyslexia and specific language impairment (SLI) are represented on a two-dimensional space where individuals with dyslexia may present impaired phonological skills but unimpaired nonphonological skills, while those with SLI may present impairments on both language skills that affect learning to read. Furthermore, this model leaves open the possibility that readers who face difficulties can develop and use compensatory skills. According to the model, students with dyslexia may therefore rely more on their available unimpaired cognitive resources to offset their decoding difficulties. The main objective of the present study is to identify certain skills, and specifically vocabulary skills, that French university students with dyslexia have developed, and that may have contributed to the development of their literacy skills, thus allowing them to successfully pursue studies at the university level.

Some studies suggest that written word recognition and reading comprehension are weakly associated in adults with dyslexia. It has been shown that university students with dyslexia can attain a level of written comprehension comparable to normal adult readers of the same chronological age (Bruck, 1990; Lefly \& Pennington, 1991; Miller-Shaul, 2005; Parrila, Georgiou, \& Corkett, 2007), particularly when time constraints are removed (Lesaux, Pearson, \& Siegel, 2006). Interestingly, Ransby and Swanson (2003) showed that the reading comprehension of these readers is mainly explained by oral comprehension, rather than written word recognition. A regression analysis showed that the reading comprehension performance of university students with dyslexia was mediated not only by phonological processing but also by several other key cognitive processes, such as oral comprehension and vocabulary skills. Crucially, using regression analyses in a sample of unimpaired children (in Grades 1 and 6), Ouellette and Beers (2010) showed that vocabulary predicted both decoding and reading comprehension in Grade 6 but not in Grade 1, with a stronger contribution to reading comprehension. In addition, using structural equation modeling in a large sample of skilled adult readers, Guo, Roehrig, and Williams (2011) showed that vocabulary knowledge was the most important factor in reading comprehension, and highlighted the relevance of measures of vocabulary in explaining individual differences in reading (Ouellette \& Shaw, 2014). Taken together, these results suggest that oral vocabulary plays a greater role, and decoding a lesser role, in explaining the reading comprehension of more proficient readers. It is therefore important to consider variables other than written word recognition and phonological processing in order to understand how adults with dyslexia are able to use other skills to compensate for their deficits and attain a high level of reading comprehension.

Recently, the role of oral language skills in explaining reading performance has been increasingly emphasized. Vocabulary knowledge, a key component of oral language skills, is now considered an essential component of reading performance both in normally developing readers (Ouellette, 2006; Ouellette \& Beers, 2010; Tunmer \& Chapman, 2012) and in skilled adult readers (Guo et al., 2011). Evidence has been presented that preserved semantic skills may be used as a compensatory strategy in reading development in dyslexia (Elbro \& Arnbak, 1996; Quémart \& Casalis, 2015; Snowling, 2000). Snowling and colleagues, notably, have suggested that dyslexic readers may be able to compensate for decoding deficits to some extent by relying on semantics and/or contextual cues to support decoding processes (Bishop \& Snowling, 2004), probably by using intact oral language skills to "bootstrap" impaired decoding process (Hulme \& Snowling, 1992; Nation \& Snowling, 1998). In adults, only a few studies have evaluated the semantic skills of university students with dyslexia by assessing vocabulary knowledge. Some have done so in order to characterize the verbal performance of individuals with dyslexia and their control group, while others have used vocabulary as a control variable to match control and dyslexic participants. It is not clear from these studies whether or not dyslexics in fact show a deficit in vocabulary skills. Two components of vocabulary skills can be distinguished (Ouellette \& Beers, 2010; Ouellette \& Shaw, 2014): vocabulary breadth and vocabulary depth. Breadth is the quantitative dimension of vocabulary: it consists in the number of words forms stored in the vocabulary system, and is typically assessed by tests such as the PPVT (Dunn \& Dunn, 1981). Depth is the qualitative dimension of vocabulary: the extent of word meaning or semantic knowledge, as in the vocabulary subtest of the WAIS-3 (Wechsler, 1997) or the BNT (Kaplan, Goodglass, \& Weintraub, 1983). 
In tests of vocabulary breadth, university students with dyslexia have been found to perform either below normal for their age (e.g., Bruck, 1990; Corkett \& Parrila, 2008; Ransby \& Swanson, 2003) or in the normal range (e.g., Perez, Majerus, \& Poncelet, 2013; Trainin \& Swanson, 2005; Vukovic, Wilson, \& Nash, 2004; Wilson \& Lesaux, 2001), with standard scores varying between 93 and 122 for both groups $(M=100$; $S D=15)$. Dyslexics have generally been found to show vocabulary depth equivalent to that of normal readers (e.g., Hatcher, Snowling, \& Griffiths, 2002; Jones, Braningan, Parra, \& Logie, 2013; Brien, Van Order, \& Pennington, 2013; Vukovic et al., 2004; Warmington, Stothard, \& Snowling, 2013; Wilson \& Lesaux, 2001; Wiseheart, Altmann, Park, \& Lombardino, 2009). Only one study has reported impaired vocabulary depth in university students with dyslexia relative to chronological age controls (Snowling, Nation, Moxham, Gallagher, \& Frith, 1997). In studies reporting standard scores on vocabulary depth tasks, both dyslexic and control readers obtained scores between 10 and 13 (scaled scores). Despite the fact that all of the cited studies were conducted with university students with dyslexia, there are no clear overall outcomes with regard to vocabulary. One explanation might be linked to the fact that the dyslexic participants in some studies were diagnosed during childhood (Corkett \& Parrila, 2008; Ransby \& Swanson, 2003) while in others they had either been diagnosed or had their diagnosis confirmed in adulthood (Trainin \& Swanson, 2005). As shown by Deacon, Cook, and Parrila (2012) for reading comprehension and reading rate, this distinction may be useful in interpreting some of the reported differences in certain reading-related skills (e.g., vocabulary).

Exposure to written language is an important generator of vocabulary (Nagy \& Herman, 1987), and the transparency of a language's orthographic system has an impact on both the acquisition of reading skills (see Share, 2004) and the manifestations of dyslexia (see Martin et al., 2010, for results from French university students with dyslexia; see SprengerCharolles \& Colé, 2013, for a review). Although it is not confirmed, it may thus also impact the development of vocabulary skills. In the grapheme-to-phoneme (i.e., reading) direction, French orthography is far more transparent than English (which is less true in the phoneme-to-grapheme direction: see Rey, Ziegler, \& Jacobs, 2000; Ziegler, Jacobs, \& Stone, 1996). This relative grapheme-to-phoneme consistency may therefore be expected to lead to a lesser penalty on accessing lowfrequency words, making it easier for French university students with dyslexia to increase their vocabulary size. If vocabulary skills can help French university students with dyslexia to read, we may hypothesize that the performance of students with dyslexia will be at least equivalent to that of age-matched controls on vocabulary tasks. To overcome the limitations of $H_{0}$ interpretation and verify the validity of the data, we used two methodologies: one based on directly assessing participants' skill on the basis of item difficulty in the vocabulary tasks (Rasch model), and one based on precisely comparing each participant's performance to that of the control group (single case studies). For this purpose, two tasks were administered to the two groups (dyslexic and control), assessing the breadth and depth of vocabulary knowledge respectively. In both cases, the rating scale and single-case allow to measure the competency of each participant objectively with respect to the difficulty of the task, and to situate it in relation to a control group. The two methods provide different statistical parameters which are sufficient to determine the participant's level of a given skill while avoiding the limitations of group analyses.

In our analysis of vocabulary performance we used the Rasch rating scale model (RSM: Andrich, 1978). Reading researchers frequently require participants to give responses to a series of individual items, each of which is typically then scored " 1 " for a correct response or " 0 " for an incorrect response. Next, each participant's scores are summed across items in order to arrive at an aggregate score for analysis. One problem with this process is that the difficulty of the individual items is presumed to be at least approximately identical. If this assumption holds, then the item scores can legitimately be summed to provide a total test score. Unfortunately, the applicability of this assumption to a given data set is rarely tested. In contrast, the Rasch model expresses the probability of a person correctly answering a test item as a logistic function of the difference between the person and some item parameter. In this model, performance differs according to both the individual's competence and the difficulty of a given item (Freitas, Prieto, Simões, \& Santana, 2014; Gutman, DeDe, Michaud, Liu, \& Caplan, 2010). The Rasch model yields measures of individuals and items on an interval scale, measured in a unit called a "logit." Another reason we used the Rasch model was its "specific objectivity" (Wright \& Douglas, 1986). This property means that the comparison of any two individuals who have been tested should be independent of which particular items are included in the test. Symmetrically, "it ought to be possible to compare items measuring the same competency independent of which particular individuals were instrumental for comparison" (Rasch, 1960, 1980). Group differences might appear not only in total scores, but also in the groups' patterns of performance across levels of item difficulty. We also provide here a method that allows neuropsychologists and speech therapists to directly compare an individual participant's performance to that of a control group. For this purpose, we present our results as a set of multiple case studies using the method of Crawford, Garthwaite, and Porter (2010). One of the limitations of studying pathological participants as a group is the impossibility of taking their heterogeneity into account. The methodology of single case studies allows us to take this variability into account by comparing the performance of individuals with dyslexia to that of the overall control group.

\section{Method}

\subsection{Participants}

Forty participants - 20 university students with dyslexia (DYS) and 20 chronological-age controls (CAC) - agreed to participate in this study. Both groups were recruited at Aix-Marseille University (France). Note that in France, unlike other countries, there is no selection process before entering university (any holder of a high school diploma is admitted). Within 


\begin{tabular}{lcr}
\hline & University students with dyslexia & Chronological-age controls \\
\hline Chronological age & $23.7(4.3)$ & $24.1(4.2)$ \\
Years of higher education & $3.0(1.4)$ & $3.05(1.3)$ \\
Reading score (CTL) & $314.8(63.5)$ & $508.1(46.3)$ \\
ARHQ questionnaire & $.86(.11)^{* * * *}$ & $.16(.14)$ \\
Raven's matrices (raw scores, $\max =58)$ & $48.55(4.1)$ & $49.05(4.0)$ \\
\hline
\end{tabular}

*** $p<.001$.

the dyslexic group, $60 \%$ of the participants were enrolled in social science programs (e.g., psychology, law, economics, or archeology) and $40 \%$ were enrolled in science programs (e.g., neurosciences, pharmacy, medicine, chemical physics, or mathematics). Within the control group, $65 \%$ of the participants were enrolled in social science programs and $35 \%$ were enrolled in science programs. University students with dyslexia were recruited following a diagnosis of dyslexia established by CERTA (Centre de Référence des Troubles d'Apprentissages [Center for the diagnosis of learning disabilities] - Hôpital Salvator, Marseille). The dyslexics had been diagnosed during primary school, and $90 \%$ had received remedial teaching, for an average of 5.44 years $(S D=31)$. Moreover, all reported that they had experienced major difficulties in learning to read when they were children. They also had to: (1) be monolingual native speakers of French, (2) lack any known neurological/ psychiatric disorders and report normal or corrected-to-normal hearing or vision, (3) have a nonverbal IQ within the normal range (that is, above the 25th percentile on Raven's Matrices: Raven, Court, \& Raven, 1995), (4) present a reading score at least 2 SD below the mean of the CAC group on the Alouette test (mean $z$-score $=4.1$; SD = 1.3; range: 209-415; Cohen's $d=3.4$ ), and (5) score above the cutoff score of .43 (Bjornsdottir et al., 2013) on the French version of the Adult Reading History Questionnaire (ARHQ, a self-report questionaire: Lefly \& Pennington, 2000). The Alouette test (Lefavrais, 1967, 2005), a standardized French reading test employed in the study of developmental dyslexia (see Martin et al., 2010; Martin, Frauenfelder, \& Colé, 2013), was used to obtain reading scores (the "CTL" index was used). ${ }^{1}$ Participants in the control group had normal literacy skills and no previous history of any learning disability according to the ARHQ self-report questionnaire. The two groups were matched on gender (each group was composed of 14 women and six men), chronological age $(t(38)=40, p>.80)$, education level $(t(38)=11, p>.90)$, and nonverbal IQ $(t(38)=.38, p>.90)$, and differed significantly on mean reading score $(t(38)=-10.9, p<.001)$ and ARHQ score $(t(38)=16,7 ; p<.001)$. These results are given in Table 1 .

\subsection{Experimental tasks}

Pretest tasks were administered to assess the participants' reading skills, phonemic awareness, syllabic awareness, and phonological short-term memory. The tests were taken from EVALEC, a computerized battery of tests of reading and readingrelated skills for French elementary school children (Sprenger-Charolles, Colé, Béchennec, \& Kipffer-Piquard, 2005). In France, there are no such computerized tests for adults (see Martin et al., 2010, 2013). Vocabulary knowledge was assessed using two different measures.

\subsubsection{Reading measures}

Two tasks were used to assess the lexical and sublexical reading procedures. For the lexical procedure we used an irregular word reading task, and for the sublexical procedure we used a pseudoword reading task. Reading time and accuracy were measured. To measure reliability on these tasks, Cronbach's alphas were calculated. On the pseudoword reading task, the Cronbach's $\alpha$ was .99 for accuracy and .96 for response time. On the irregular word reading task, the Cronbach's $\alpha$ was .79 for accuracy and .76 for response time.

\subsubsection{Phonemic awareness}

In the test used to assess phonemic awareness, the participants had to delete the first phoneme from a pseudoword composed of three phonemes. The test consisted of 12 items with a consonant-consonant-vowel structure (CCV: e.g., spo). The participants heard the items one by one through headphones, and had to repeat each item as accurately as possible, omitting its first phoneme, with no time limit. Time taken to complete each task (response time) and accuracy were measured. Cronbach's $\alpha$ was .78 for accuracy and .91 for response time.

\subsubsection{Syllabic awareness}

In this test, participants had to delete the first syllable of a pseudoword with a trisyllabic structure. This test included 10 items with a simple consonant-vowel syllabic structure (e.g., povidu). The procedure was identical to the phonemic awareness task. Cronbach's $\alpha$ was .93 for response time; Cronbach's $\alpha$ was not calculated for accuracy because the participants performed at ceiling level on the task.

\footnotetext{
${ }^{1}$ The CTL score takes both accuracy and speed into account. $\mathrm{CTL}=\left(C^{*} 180\right) / \mathrm{TL}$; with $\mathrm{C}=$ number of words read correctly, and $\mathrm{TL}=\mathrm{reading}$ time.
} 
Mean Performance ${ }^{a}$ (Standard Deviation) and Effect Size (Cohen's d) for University Students with Dyslexia and CA Controls on Tests of Word Reading and Phonological Skills.

\begin{tabular}{|c|c|c|c|c|}
\hline & & $\begin{array}{l}\text { University students } \\
\text { with dyslexia }\end{array}$ & $\begin{array}{l}\text { Chronological-age } \\
\text { controls }\end{array}$ & $\begin{array}{l}\text { Effect size } \\
\text { (Cohen's } d \text { ) }\end{array}$ \\
\hline $\begin{array}{l}\text { Pretests } \\
\text { Pseudowords }\end{array}$ & $\begin{array}{l}\text { Accuracy (\%) } \\
\text { Response time (ms) }\end{array}$ & $\begin{array}{c}90.2(6.9)^{* * * *} \\
1308(419)^{* * *}\end{array}$ & $\begin{array}{c}97.7(2.4) \\
631.3(118.3)\end{array}$ & $\begin{array}{l}1.4 \\
3\end{array}$ \\
\hline Irregular words & $\begin{array}{l}\text { Accuracy (\%) } \\
\text { Response time (ms) }\end{array}$ & $\begin{array}{c}95.5(4.26) \\
988(231.5)^{* * *}\end{array}$ & $\begin{array}{c}97.75(3.79) \\
638.9(100.84)\end{array}$ & $\begin{array}{l}0.5 \\
1.9\end{array}$ \\
\hline Phonemic awareness (CCV) & $\begin{array}{l}\text { Accuracy (\%) } \\
\text { Response time (s) }\end{array}$ & $\begin{array}{l}89.5(9.7)^{* * * *} \\
31.9(7.8)^{* * *}\end{array}$ & $\begin{array}{l}98.7(3) \\
16.1(4)\end{array}$ & $\begin{array}{l}1.2 \\
2.5\end{array}$ \\
\hline Syllabic awareness (TRISYL) & $\begin{array}{l}\text { Accuracy (\%) } \\
\text { Response time (s) }\end{array}$ & $\begin{array}{l}97(5.6) \\
26.6(5.6)^{* * * *}\end{array}$ & $\begin{array}{l}97(6.5) \\
17.8(4.5)\end{array}$ & $\begin{array}{l}0 \\
1.7\end{array}$ \\
\hline Phonological STM & $\begin{array}{l}\text { Accuracy (span) } \\
\text { Response time (s) }\end{array}$ & $\begin{array}{c}4.5(0.8)^{* * * *} \\
60.8(13.5)^{* * *}\end{array}$ & $\begin{array}{r}5.3(0.5) \\
46.7(4.5)\end{array}$ & $\begin{array}{l}1.1 \\
1.4\end{array}$ \\
\hline
\end{tabular}

${ }^{*} p<0.05$.

*** $p<0.01$.

*** $p<0.001$.

a Given the use of the Rasch rating scale, the groups' raw scores on the two vocabulary measures are not presented here. However, for purposes of comparison with previous studies on these tasks, standard scores (and standard deviations) are presented below. On vocabulary breadth task, the mean standard score for the dyslexic group was $116.3(\mathrm{SD}=7.6$ ) and for the control group it was 115.7 ( $(\mathrm{SD}=6.5)$ On vocabulary depth task, the mean scaled score for the dyslexic group was $14.2(\mathrm{SD}=2.7)$ and for the control group it was $12.1(\mathrm{SD}=2.9)$.

\subsubsection{Phonological short-term memory}

This task consisted of repeating pseudowords aloud (e.g., moukola). Twenty-four pseudowords from three to six syllables long were presented in increasing order of syllable length. The participants heard the items one by one through headphones, and had to repeat each item as accurately as possible, with no time limit. Time taken to perform the whole task (response time) and accuracy were measured. Cronbach's $\alpha$ was .68 for accuracy and .92 for response time.

\subsubsection{Vocabulary breadth}

The Echelle de Vocabulaire en Images Peabody (EVIP: Dunn, Thieriault-Whalen, \& Dunn, 1993; the French adaptation of the Peabody Picture Vocabulary Test-Revised, PPVT-R; Dunn \& Dunn, 1981) was administered. The test stimuli consist of 51 items of increasing difficulty. The test is intended for participants older than 16 years. In each trial, four different pictures were presented on the computer screen, and a word was presented through headphones. Participants were expected to match the word to the corresponding picture on the computer screen. Accuracy was measured. Correct responses received one point and errors received a score of zero. We did not analyze standard scores because of the use of the Rasch rating scale model, but they are presented in Table 2.

\subsubsection{Vocabulary depth}

Vocabulary depth was measured using a definition task that assesses the accuracy and precision of word knowledge. We used the vocabulary subtest of the Wechsler Adult Intelligence Scales, 3rd edition (WAIS-3; Wechsler, 1997). The test consists of 33 items. An examiner said a word (e.g., refuge) and the participants were asked to define it. We scored each item response in accordance with the test manual, awarding zero, one, or two points depending the accuracy and precision of the response. We did not analyze standard scores because of the use of the Rasch rating scale model, but they are presented in Table 2.

\subsubsection{Reading history}

The French version of the ARHQ a self-report questionnaire (Lefly \& Pennington, 2000) was administered. This scale is a useful instrument in clinical practice for screening for dyslexia in adults. It includes items on reading habits, reading and spelling abilities, reading speed, attitudes toward school and reading, additional assistance received, repeating grades or courses and effort required to succeed, separately for elementary school, secondary school, post-secondary education, and current life (Deacon et al., 2012). Reliability (Cronbach's $\alpha$ ) for our participants was .92 (for comparison, reliability was .93 in Deacon et al., 2012; and .96 in Kirby, Silvestri, Allingham, Parrila, \& La Fave, 2008). A global score was calculated by totaling the points on the items and then dividing by the maximum possible score. Scores could range from a low of 0 to a high of 1 , with a lower score indicating less reading difficulty.

\section{Results}

The mean scores and effect sizes (Cohen's $d$ ) of the DYS and CAC groups on the pretests are given in Table 2.

On the pseudoword reading, phonemic awareness, and phonological short-term memory tasks, the dyslexic group's performance was significantly slower and less accurate than that of CA controls (accuracy: $p<.001$; response time: $p<.001$ ). 
On the irregular word reading and syllabic awareness tasks, the response times of the dyslexic group were higher than those of CA controls $(p<001)$, but the two groups did not differ in accuracy (irregular words: $t(18)=1.6, p=.08$; syllabic awareness: $t(18)=.04, p=.90)$.

\subsection{Application of the Rasch rating scale model to vocabulary skills}

In order to establish the distribution of individual participants on these two vocabulary scales, we applied the Rasch rating scale model (RSM: Andrich, 1978), as implemented in Winsteps (Linacre, 2013), to analyze the data. As stated above,

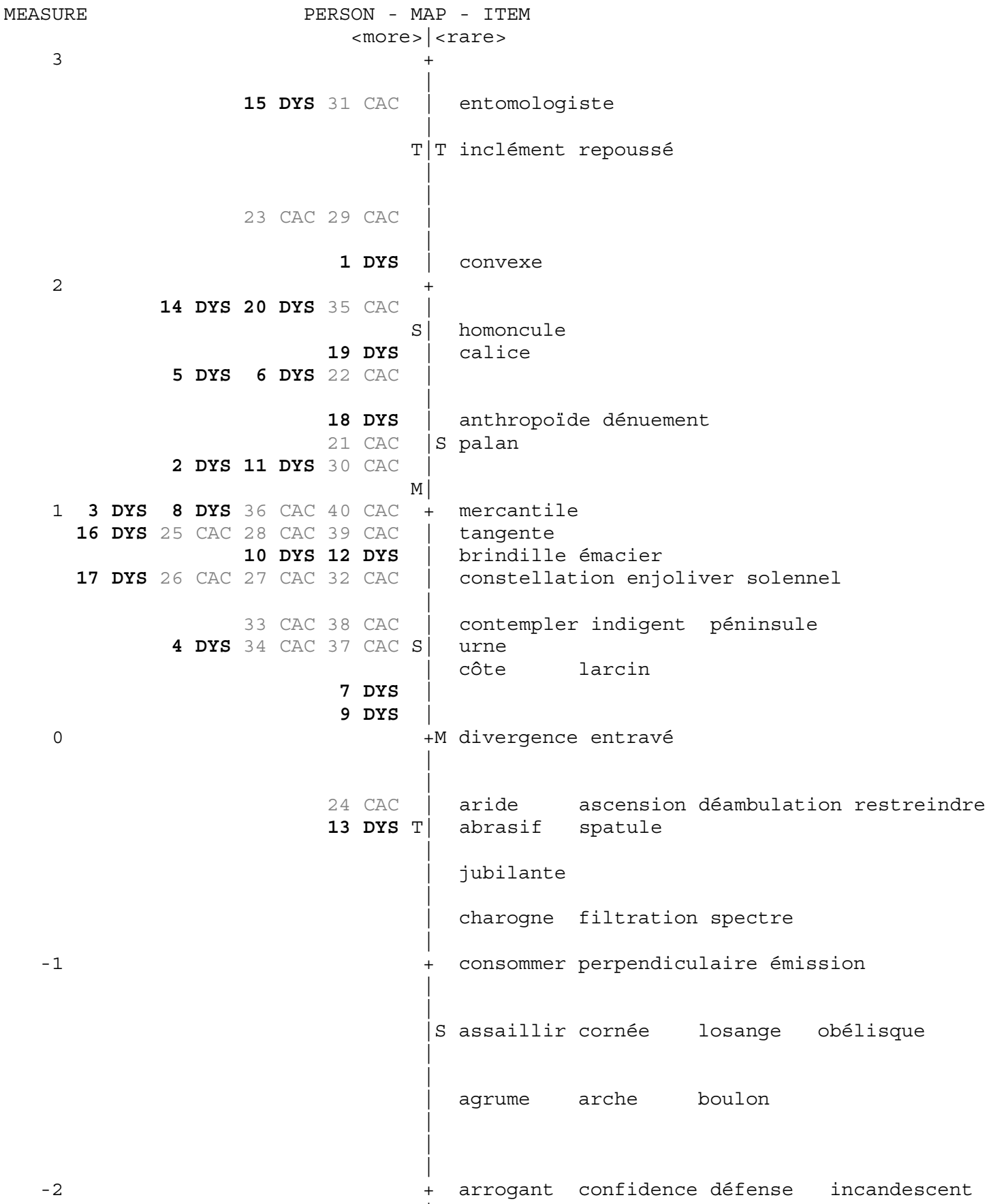
$-2$ 
the Rasch model estimates person trait and item difficulty parameters on a common metric, namely logits. The basic Rasch model is a dichotomous response model, representing the conditional probability of binary outcomes as a function of a person's trait level and an item's difficulty level. In other words, in the simple Rasch model, the probability of a correct response is modeled as a logistic function of the difference between the person's ability and the difficulty of a given item. Thus, it allowed us to test whether the difficulty levels of the EVIP and WAIS-3 scales were appropriate for the sample in this study.

Fig. 1 shows a distribution of trait levels and item difficulties on a logit scale for the 51 selected dichotomous items on the EVIP scale. The left side of the continuum shows trait levels, and the right side of the scale shows item difficulty levels. As can be seen, the targeting of the items was not optimal for the sample, since the distributions, and hence the respective parameter means and standard deviations of the items and the participants, were fairly far from each other. There is a lack of overlap between the two sides of the scale: the items and their thresholds cover a wide range of the EVIP scale, but the majority of thresholds do not cluster against the data points for the majority of participants. This shows that the instrument is not well-targeted for the sample (i.e., most of the participants are situated on the top of the scale), but given the feature of objective measurement intrinsic to the Rasch rating scale model, the measure does not change (see Wright \& Douglas, 1986 , for a detailed explanation). Moreover, the distribution of person trait levels was independent of the group. The means for the chronological age control and university students with dyslexia groups were $1.09(\mathrm{SD}=73)$ and $1.14(\mathrm{SD}=74)$ respectively,

MEASURE

4

3

2

1

0

$-1$
PERSON - MAP - ITEM

$<$ more $>$ |<rare $>$

conjecture

émulation

| T

invectiver prosaïque

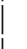

$\mathrm{T} \mid$

14 DYS 18 DYS

15 DYS 21 CAC

1 DYS

2 DYS

8 DYS 17 DYS 19 DYS 29 CAC

6 DYS 20 DYS

25 CAC 35 CAC

3

4 DYS 11 DYS 12 DYS 23 CAC 37 CAC 39

13 DYS 3

7 DYS 9 DYS 10 DYS 26 CAC 28 CAC 36

CAC

$\mathrm{CAC}$

5 DYS

4 CAC $\mathrm{S}+\mathrm{M}$

32 CAC 40

16 DYS 24

$30 \mathrm{CAC}$

38 CAC

33 CAC T

connivence

pittoresque

$S$

|

+ apologie

apologie

vigoureux

évasif

evasif

assimiler concertation sauvage

initiative

contracter esquisse hier

calendrier grandiose mime

irritable

hétérogène sanction

confier refuge élaborer

persévérer

$S$ instruire

baleine héréditaire

arracher

<less $>$ |<frequent $>$

Fig. 2. Variable map: distribution of person trait level and item difficulty level for the 30 WAIS-3 items, in logits. Right: difficulty of each item. Left: skill level of each participant. 
and a one-way analysis of variance on the subtotal means showed that the students with dyslexia and controls did not statistically differ $(F(1,38)=.06 ; p=.804$, Cohen's $d=.068$, indicating a very small effect).

Fig. 2 presents a distribution of person trait levels and item difficulties on a logit scale for the 33 dichotomous items on the WAIS-3 scale. On this scale, in contrast to the EVIP scale, the distribution of person trait levels differed between the two groups. The means were $.45(\mathrm{SD}=77)$ and $.90(\mathrm{SD}=58)$ for the control and dyslexic groups respectively, and a one-way analysis of variance for the subtotal means showed that there was a statistical difference between these means $(F(1,38)=4.15 ; p=.046$; Cohen's $d=.660$, indicating a medium effect size $)$.

Our results for vocabulary breadth showed that students with dyslexia and controls were distributed in the same way in relationship to item difficulty. For vocabulary depth, however, the university students with dyslexia were more successful than controls on the most difficult items. The difficulty of items on the EVIP and WAIS scale is known to depend on word frequency. We thus conducted a hierarchical regression analysis to determine whether the item difficulty obtained with the Rasch scale was explained by psycholinguistic variables such as oral frequency, number of phonemes, number of syllables, phonemic uniqueness point, number of phonological neighbors, and morphological complexity. The results showed that only oral $\log$ frequency explained item difficulty $(F(1 ; 28)=14.11 ; p<.001)$.

In addition, in order to control the effect of reading history on the dyslexic group's level of vocabulary, we computed a reading habits score (based on the 15 related items from the ARHQ self-report questionnaire) and calculated its correlations with Rasch measures of vocabulary breadth and depth. The results showed no significant correlations between reading habits and vocabulary breadth $(r(19)=.27 ; p=21)$ or depth $(r(19)=20 ; p=39)$. Reading habits explained a non-significant $7.2 \%\left(R^{2}\right)$ of the variance in vocabulary breadth and a non-significant $4 \%\left(R^{2}\right)$ of the variance in vocabulary depth.

\subsection{Single-case studies}

In order to assess each dyslexic participant's vocabulary skills in relationship to the control group, we used the methodology of single-case studies (Crawford et al., 2010). Generally, the aim of this type of methodology is to determine whether a particular patient exhibits a significant deficit in comparison to a control group. One approach is to convert the patient's score to a $z$ score based on the mean and the standard deviation of the control sample. The crucial problem with this is that it treats the control sample as if it was a population and then treats the sample statistics as population parameters (see Atzeni, 2009). When the size of the control sample is large these parameters converge, but when the size of the control sample is small this approach leads to an inflation of Type I error and a risk of overestimating the abnormality of a patient's score. The methodology developed by Crawford et al. (2007, 2010) includes additional criteria to obtain a point estimate of the effect size and interval estimates of the abnormality of the case's score. The tables in Appendices A and B give the means and standard deviations for controls on the task (and control $n$ ); the raw score of the single case; the point estimate of the effect size $\left(z_{c c}\right)$ for the difference between the case and controls, accompanied by the corresponding $95 \%$ confidence interval; the $t$-value and its associated probability, obtained through the application of Crawford and Howell's (1998) test or its Bayesian equivalent (Crawford \& Garthwaite, 2007); and, finally, the point estimate of the percentage of the control population who obtained a higher score than the individual in the case and the corresponding 95\% confidence interval (Crawford \& Garthwaite, 2007). All of the aforementioned results can be obtained using the computer programs Singlims_ES.exe (Crawford et al., 2010), which implements classical methods for comparison of a single case's score to scores from a control sample.

Fig. 3 shows that in the comparison of single cases to the control group on the EVIP task, eight of the participants with dyslexia scored lower than the control group mean, and in five cases the control group mean fell outside of the 95\%

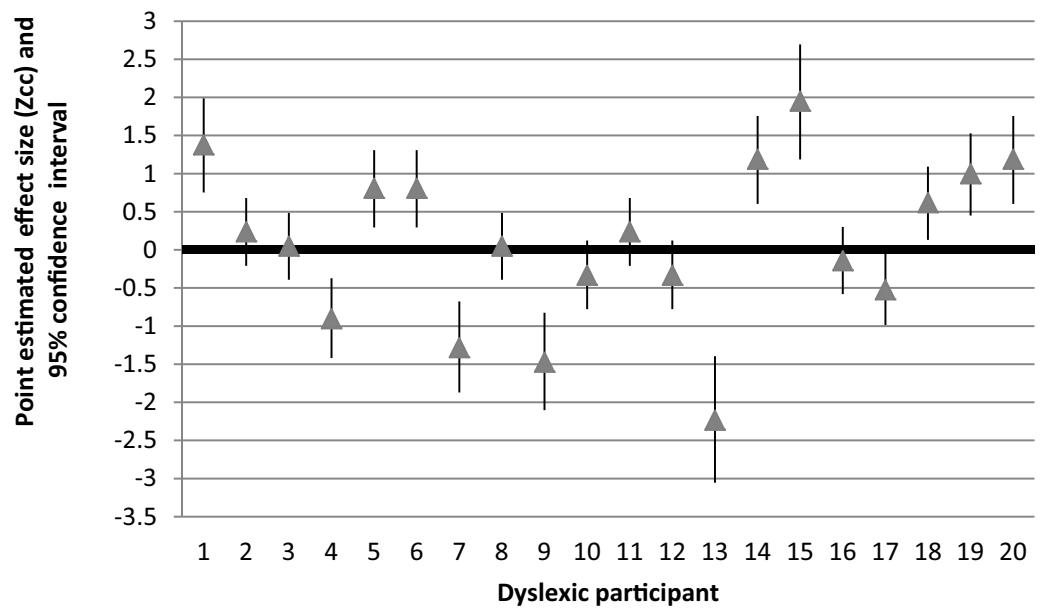

Fig. 3. Point estimates of effect size and the corresponding 95\% confidence intervals for each dyslexic participant on the EVIP task, in comparison to controls. The baseline (in black) shows the control mean $(M=35.75 ; \mathrm{SD}=5.26 ; N=20)$. 


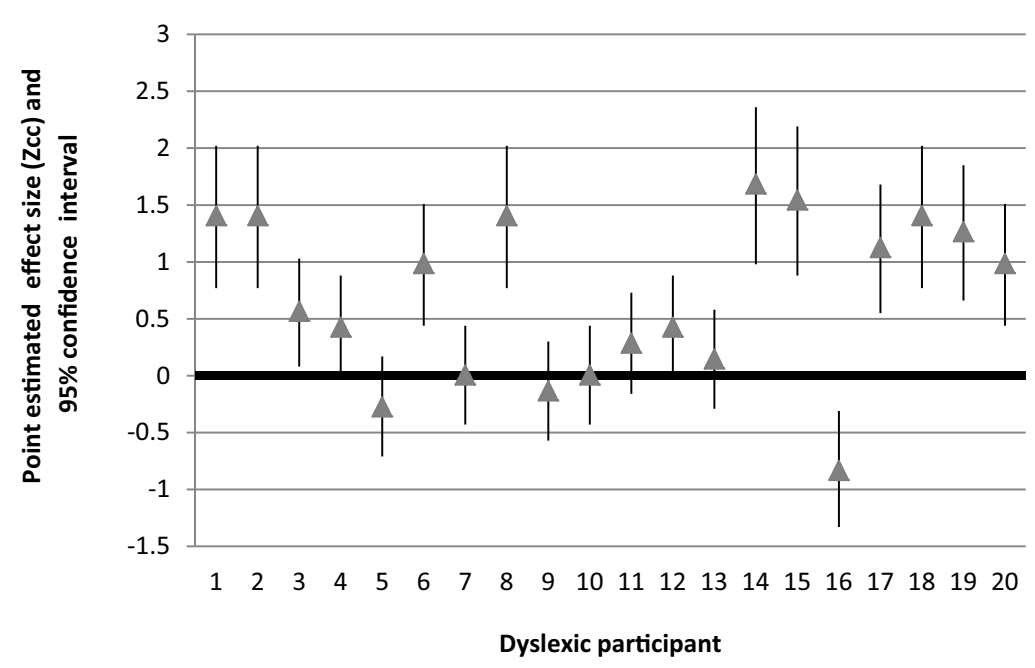

Fig. 4. Point estimate of the effect size and the corresponding 95\% confidence interval for each dyslexic participant on the WAIS task compared to controls. The baseline (in black) shows the control mean $(M=41.95 ; \mathrm{SD}=7.15 ; N=20)$.

confidence interval for the estimated effect size ( $z_{\mathrm{CC}}$; participants $4,7,9,13,17$ ). The other 12 participants with dyslexia scored higher than the control group; in eight of these cases the control group mean fell outside of the $95 \% \mathrm{CI}$ for the estimated effect size (participants 1, 5, 6, 14, 15, 18, 19,20). The estimated percentage of the control population who scored higher than the cases shows that in general, the university students with dyslexia performed at the same level as the control group on tests of vocabulary breadth.

Fig. 4 presents the results of comparisons of the results of students with dyslexia on the WAIS-3 task to the control group. It shows that only three participants scored lower than the control group mean, and the control group mean only fell outside of the $95 \% \mathrm{CI}$ for the estimated effect size in one case (participant 16). The other 17 dyslexic participants scored higher than the control group mean, and in 11 cases the $95 \% \mathrm{CI}$ for the estimated effect size did not include the control mean (participants $1,2,3,6,8,14,15,17,18,19,20)$. Collectively, these results suggest that despite inter-individual differences, French university students with dyslexia outperformed the control group on the vocabulary depth task.

Finally, single-case scores were computed on the set of phonological and literacy tasks to further investigate whether dyslexia may involve a pattern of dissociation between phonological and semantic skills, as suggested by the model of Bishop and Snowling (2004). Here we present the number of dyslexic participants who scored significantly lower than the control group, the cutoff value for significance, and the minimum - maximum point estimate of effect size. For the pseudoword reading and phoneme awareness tasks we computed efficiency scores, calculated as the number of correct responses per second, because of the ceiling performance of the control group for accuracy. The results showed that all 20 dyslexic participants scored significantly lower than the control group on pseudoword reading $[-1.7 ;-4.7]$ (all $p<.05)$ and phoneme awareness $[-2 ;-3.6]$ (all $p<.01$ ). For the syllabic awareness and irregular word reading tasks, we computed single-case analyses only on response times due to ceiling effects on accuracy. The results showed that 15 dyslexics scored significantly lower than the control group on syllabic awareness $[-1 ; 7 ;-5.8]$ (all $p<.05$; cutoff value $=25.4 \mathrm{~s}$ ) and that 18 dyslexics performed below controls on irregular word reading $[-1.7 ;-10.3]$ (all $p<.05$; cutoff value $=818$ ms). Finally, the results of the phonological short-term memory task showed that while only 10 dyslexic participants showed an effect size below that of the control group for span $[-2,7 ;-4,7]$ (all $p<.01$; cutoff score $=4$ ), all but one (19) showed slower performance than controls $[-1.8 ;-11.2]$ (all $p<.05 ;$ cutoff value $=53 \mathrm{~s}$ ).

\section{Discussion}

Vocabulary skills are considered a key component in the modeling of reading acquisition (Tunmer \& Chapman, 2012) and skilled reading (Guo et al., 2011). Individuals with dyslexia may draw on these skills as a compensatory strategy when reading (Snowling, 2000). The main objective of this study was to precisely assess vocabulary in university students with dyslexia in order to examine whether or not these skills may help these readers compensate for their persistent phonological and visual word recognition deficits. We used two vocabulary tasks, evaluating vocabulary breadth and depth respectively. Our hypothesis was that the dyslexic participants' performance on these two tasks would be at least equivalent to that of controls. The Rasch model showed that in the vocabulary breadth task the two groups performed at the same level, while dyslexics systematically outperformed their CA controls in the vocabulary depth task. This pattern of results was supplemented by multiple case studies.

The control group outperformed university students with dyslexia on a set of tasks assessing various forms of phonological processing that involved in reading. On the pseudoword reading, phonemic awareness, and phonological STM 
tasks, the performance of university students with dyslexia was significantly slower and less accurate than that of CA controls in both group and single-case comparisons. These results replicate the findings of numerous studies with adults with dyslexia (Martin et al., 2010; Ramus et al., 2003). Moreover, when reading irregular words, the response times of university students with dyslexia were longer than those of CA controls, replicating Martin et al.'s (2010) results with French-speaking participants. In contrast, the accuracy of the two groups' performance did not differ; but because the two groups showed near ceiling performance it is difficult to interpret this pattern of results, which again closely parallels that of Martin et al. (2010). One possible explanation for these results could be the fact that there are very few irregular words in French, mainly high-frequency words, allowing university students with dyslexia to read them as accurately as their CA controls. These results differ from those obtained in English-speaking adults with dyslexia (but see Siegel, Share, \& Geva, 1995, for a demonstration of the superior "orthographic skills" of English children with dyslexia), in whom the lexical/ orthographic procedure involved in reading irregular words has been reported to be deficient (Bruck, 1990). The relative transparency of French orthography may have helped these dyslexic readers to develop orthographic skills (Martin et al., 2010). Furthermore, one study reported evidence that the orthographic processing of university students with dyslexia improves with time, and that frequent exposure to print may be an important factor in ensuring the development of orthographic skills (Miller-Shaul, 2005).

Rasch analyses of performance on the vocabulary breadth task revealed no significant differences in vocabulary knowledge between the two groups. This result was confirmed in the multiple case-study analysis. On the vocabulary depth task, however, Rasch analyses showed that the university students with dyslexia outperformed CA controls. These Frenchspeaking dyslexics defined orally presented words more precisely than their control group peers, a result that again was confirmed by the multiple case-study analysis. Interestingly, neither form of vocabulary performance correlated with a measure of reading habits (ARHQ questionnaire), suggesting that our results on vocabulary are likely not due to print exposure. The vast majority of studies in this area have been conducted with English-speaking individuals, and metaanalyses conducted by Swanson and Hsieh (2009) and Swanson (2012) showed that the vocabulary skills of this population are significantly inferior to those of normal-reading controls. However, in both cases vocabulary breadth and depth were considered together, and the participants in the studies surveyed in these meta-analyses may have included both students and non-students with dyslexia. The vocabulary skills of the French university students with dyslexia involved in our study, in contrast, were clearly well-developed, despite persistent phonological processing deficits at both the case and group level. This pattern supports our hypothesis that strengths in vocabulary may play a role in compensatory/adaptive strategies among university students with dyslexia.

Overall, our results are consistent with previous studies proposing that individuals with dyslexia may use relatively strong semantic skills in compensatory strategies for reading development (Elbro \& Arnbak, 1996; Elbro, Nielsen, \& Petersen, 1994; Snowling, 2000). Three alternative, non-exclusive hypotheses can be advanced to explain our results. The first potential explanation is that the transparency of the French orthographic system may explain the good vocabulary performance of our dyslexic participants. Reading in French, and in transparent orthographic systems more generally, is less difficult than reading in English (Paulesu et al., 2001), meaning that low-frequency words can be decoded more easily. This could explain, for example, why French university students with dyslexia performed well with low-frequency words on both of the two vocabulary tasks.

The second hypothesis relates to the activation of stored word representations in adults with dyslexia. Ramus and Szenkovits (2008) suggest that the phonological deficit in dyslexia results from impaired access to phonological forms and the incurred memory load, rather than from degraded phonological representations. Recently, a study combining functional magnetic resonance imaging with multivoxel pattern analysis (Boets et al., 2013) showed that adults with dyslexia have intact phonetic representations, but cannot easily access them because of impaired neural connections. In contrast, semantic knowledge associated to words seems to be preserved in both children with dyslexia (Vellutino, Scanlon, \& Spearing, 1995) and adults with dyslexia (Elbro et al., 1994). This is consistent with the model of Bishop and Snowling (2004), which postulates that phonological skills are impaired in dyslexia, but nonphonological skills are preserved. Successful activation of semantic knowledge during the vocabulary tasks may thus explain the skill level that we observed in our dyslexic population. Two neuroimaging studies found that the spatial distribution of brain areas involved in semantic processing did not differ between dyslexic and skilled readers, although the timing and strength of activation clearly did differ (Helenius, Salmelin, Service, \& Connolly, 1999; Rüsseler, Becker, Johannes, \& Münte, 2007). However, this pattern of results could be related to an integration process required by two of the tasks used in the two studies, the incongruent semantic task and the reading task.

Finally, the third possible explanation, which is complementary to the previous two, is that university students with dyslexia use different cognitive strategies to address the vocabulary depth task. On the vocabulary breadth task, participants must match a word to a picture. This task does not involve language production, and here the performance of the dyslexic group was equivalent to that of CA controls. In contrast, university students with dyslexia outperformed CA controls on the vocabulary depth task, which requires participants to give a precise definition of each word, potentially measuring oral language skills more broadly. Two types of knowledge can be used to respond on this task. The first is a form of language knowledge and consists of information (orthographic, phonological, and semantic) stored in the representation of the word to be defined. The second is world knowledge about the concept corresponding to the word. Adults with dyslexia might benefit from the possibility of relying on the latter form of knowledge to perform the task, suggesting a difference between the task processing strategies of skilled readers and dyslexic readers. In line with this hypothesis, the vocabulary depth task 
can also be viewed as an oral metalinguistic task. Remedial teaching is often partly based on the use of such metalinguistic tasks. Virtually all (95\%) of the dyslexic participants in our study had received remedial teaching, for an average of five years. Rehabilitation by means of speech therapy focusing on training to overcome deficits (e.g., phonological awareness, pseudoword reading, phoneme-to-grapheme correspondences), language (grammar and morphosyntax), as well as on reading strategies (e.g., using contextual information, textual organization, memory) may thus have favored the development of metalinguistic skills in this population. However, the possibility that the semantic skills of individuals with dyslexia can develop spontaneously cannot be ruled out.

Another point of interest of this study is that the case study method proposed by Crawford et al. (2010) is a promising tool for practitioners working with dyslexia, although it requires standardized measures with a reference group $(N \geq 15)$ as a benchmark for the participant's performance. In France, there is currently a lack of standardized tests, in particular for adults, which is not the case in the UK (Warmington, Stothard, \& Snowling, 2013). Data are generally available in French children, but many studies have highlighted differences between dyslexic adults and children in terms of reading skills (for example, see Lum, Ullman, \& Conti-Ramsden, 2013, for a meta-analysis in procedural learning; Beidas, Khateb, \& Breznitz, 2013, for executive functions) as well as reading-related skills (Miller-Shaul, 2005, for orthographic skills; and Martin et al., 2013, for morphological skills).

Our initial results on vocabulary skills in dyslexia are encouraging, and they have significant implications for both skills assessment and remediation techniques to support dyslexic readers. They suggest that it may be very important to systematically take into account both of these two dimensions of vocabulary (breadth and depth) in the diagnosis of dyslexia in adults (see Warmington et al., 2013, and Elbro, 2010 for a discussion), as it could affect the type of remediation offered to this population. For example, a study on adolescents with dyslexia (Rose \& Rouhani, 2012) showed that vocabulary has a direct impact on the fluency of oral reading. Moreover, these authors also found that vocabulary moderates the negative impact of impaired verbal working memory on oral reading fluency. These findings suggest that the oral reading fluency of adolescents with dyslexia depends on individual differences in their vocabulary knowledge. Adults with dyslexia show both good vocabulary skills and persistently slow and inaccurate reading. In this population, where remediation is rare, semantic training could have beneficial effects on reading skills, and particularly on reading fluency. Further studies should be carried out in order to find effective remedial approaches.

\section{Conclusion}

Previous studies have assessed the vocabulary skills of adults with dyslexia, but it has never been considered as a potential compensatory skill (although see Snowling, 2000). One of the vocabulary tasks we used, the vocabulary depth task, is a subtest of the WAIS-3 (Wechsler, 1997) which assesses the verbal comprehension component of general IQ. As such, it is sometimes considered a proxy for intelligence. However, this interpretation has been challenged by numerous findings (see Ouellette \& Shaw, 2014, for a discussion). Future research will have to further explore the possible role of vocabulary skills in compensating for the poor reading skills of adults with dyslexia. An important limitation of this study should also be noted which is the lack of reading comprehension assessment. The reason for this is simply there is currently no standardized reading comprehension test for adults in France. Studies using both vocabulary and reading comprehension tasks in adults with developmental dyslexia will be needed to confirm the possibility that university students with dyslexia use vocabulary skills to attain a high level of reading comprehension. Finally, given the heterogeneity of dyslexia, case studies should be conducted using batteries of standardized tests, in order to allow practitioners to achieve more accurate differential diagnoses.

\section{Appendix A. Comparison of single cases to controls on the EVIP task $(M=35.75 ; S D=5.26 ; n=20)$}

\begin{tabular}{|c|c|c|c|c|c|c|c|}
\hline \multirow[t]{2}{*}{ Subject } & \multirow[t]{2}{*}{ Case's score } & \multicolumn{2}{|c|}{ Significance test } & \multicolumn{2}{|c|}{$\begin{array}{l}\text { Estimated percentage of the } \\
\text { control population who } \\
\text { obtained a higher score than } \\
\text { the individual in the case }\end{array}$} & \multicolumn{2}{|c|}{ Point estimate of effect size $\left(z_{\mathrm{cc}}\right)$} \\
\hline & & $t$ & $p$ & Point & $(95 \% \mathrm{CI})$ & Point & $(95 \% \mathrm{CI})$ \\
\hline Subject 1 & 43 & 1.34 & 0.097 & 9.72 & $(2.34-22.61)$ & 1.378 & (0.752 to 1.987$)$ \\
\hline Subject 2 & 37 & 0.23 & 0.409 & 40.95 & $(24.84-58.31)$ & 0.238 & $(-0.210$ to 0.679$)$ \\
\hline Subject 3 & 36 & 0.04 & 0.481 & 48.17 & $(31.36-65.23)$ & 0.048 & $(-0.392$ to 0.485$)$ \\
\hline Subject 4 & 31 & -0.88 & 0.194 & 80.54 & $(64.49-92.18)$ & -0.903 & $(-1.418$ to -0.372$)$ \\
\hline Subject 5 & 40 & 0.78 & 0.220 & 22.00 & $(9.55-38.47)$ & 0.808 & (0.293 to 1.307$)$ \\
\hline Subject 6 & 40 & 0.78 & 0.220 & 22.00 & $(9.55-38.47)$ & 0.808 & (0.293 to 1.307$)$ \\
\hline Subject 7 & 29 & -1.25 & 0.112 & 88.71 & (75.08-96.93) & -1.283 & $(-1.871$ to -0.677$)$ \\
\hline Subject 8 & 36 & 0.04 & 0.481 & 48.17 & (31.36-65.23) & 0.048 & $(-0.392$ to 0.485$)$ \\
\hline Subject 9 & 28 & -1.43 & 0.083 & 91.66 & $(79.53-98.22)$ & -1.473 & $(-2.103$ to -0.825$)$ \\
\hline Subject 10 & 34 & -0.32 & 0.374 & 62.55 & $(45.14-78.20)$ & -0.333 & $(-0.779$ to 0.122$)$ \\
\hline Subject 11 & 37 & 0.23 & 0.409 & 40.95 & $(24.54-58.31)$ & 0.238 & $(-0.210$ to 0.679$)$ \\
\hline Subject 12 & 34 & -0.32 & 0.374 & 62.55 & $(45.14-78.20)$ & -0.333 & $(-0.779$ to 0.122$)$ \\
\hline Subject 13 & 24 & -2.18 & 0.021 & 97.89 & (91.85-99.88) & -2.234 & $(-3.055$ to -1.396$)$ \\
\hline Subject 14 & 42 & 1.16 & 0.130 & 13.02 & $(3.95-27.34)$ & 1.188 & (0.602 to 1.756$)$ \\
\hline
\end{tabular}




\section{Appendix A (Continued)}

\begin{tabular}{|c|c|c|c|c|c|c|c|}
\hline \multirow[t]{2}{*}{ Subject } & \multirow[t]{2}{*}{ Case's score } & \multicolumn{2}{|c|}{ Significance test } & \multicolumn{2}{|c|}{$\begin{array}{l}\text { Estimated percentage of the } \\
\text { control population who } \\
\text { obtained a higher score than } \\
\text { the individual in the case }\end{array}$} & \multicolumn{2}{|c|}{ Point estimate of effect size $\left(z_{\mathrm{cc}}\right)$} \\
\hline & & $t$ & $p$ & Point & $(95 \% \mathrm{CI})$ & Point & $(95 \% \mathrm{CI})$ \\
\hline Subject 15 & 46 & 1.90 & 0.036 & 3.62 & $(0.35-11.80)$ & 1.949 & (1.185 to 2.695$)$ \\
\hline Subject 16 & 35 & -0.13 & 0.445 & 55.46 & $(38.21-71.94)$ & -0.143 & $(-0.581$ to 0.300$)$ \\
\hline Subject 17 & 33 & -0.51 & 0.307 & 69.21 & $(51.93-83.77)$ & -0.523 & $(-0.985$ to -0.048$)$ \\
\hline Subject 18 & 39 & 0.60 & 0.276 & 27.68 & $(13.76-44.77)$ & 0.618 & $(0.131$ to 1.091$)$ \\
\hline Subject 19 & 41 & 0.97 & 0.171 & 17.11 & $(6.31-32.64)$ & 0.998 & (0.450 to 1.529$)$ \\
\hline Subject 20 & 42 & 1.16 & 0.130 & 13.02 & $(3.95-27.34)$ & 1.188 & (0.602 to 1.756$)$ \\
\hline
\end{tabular}

\section{Appendix B. Comparison of single cases to controls on the WAIS task $(M=41.95 ; S D=7.15 ; n=20)$}

\begin{tabular}{|c|c|c|c|c|c|c|c|}
\hline \multirow[t]{2}{*}{ Subject } & \multirow[t]{2}{*}{ Case's score } & \multicolumn{2}{|c|}{ Significance test } & \multicolumn{2}{|c|}{$\begin{array}{l}\text { Estimated percentage of the } \\
\text { control population who } \\
\text { obtained a higher score than } \\
\text { the individual in the case }\end{array}$} & \multicolumn{2}{|c|}{ Point estimate of the effect size $\left(z_{\mathrm{cc}}\right)$} \\
\hline & & $t$ & $p$ & Point & $(95 \% \mathrm{CI})$ & Point & $(95 \% \mathrm{CI})$ \\
\hline Subject 1 & 52 & 1.37 & 0.093 & 9.30 & $(2.16-21.98)$ & 1.406 & (0.773 to 2.020$)$ \\
\hline Subject 2 & 52 & 1.37 & 0.093 & 9.30 & $(2.16-21.98)$ & 1.406 & (0.773 to 2.020$)$ \\
\hline Subject 3 & 46 & 0.55 & 0.293 & 29.34 & $(15.07-46.54)$ & 0.566 & (0.087 to 1.033$)$ \\
\hline Subject 4 & 45 & 0.41 & 0.340 & 34.09 & $(18.94-51.47)$ & 0.427 & $(-0.037$ to 0.880$)$ \\
\hline Subject 5 & 40 & -0.26 & 0.396 & 60.35 & $(42.76-76.29)$ & -0.273 & $(-0.716$ to 0.177$)$ \\
\hline Subject 6 & 49 & 0.96 & 0.174 & 17.40 & $(6.48-33.00)$ & 0.986 & (0.440 to 1.515$)$ \\
\hline Subject 7 & 42 & 0.01 & 0.497 & 49.73 & $(32.80-66.68)$ & 0.007 & $(-0.431$ to 0.445$)$ \\
\hline Subject 8 & 52 & 1.37 & 0.093 & 9.30 & $(2.16-21.98)$ & 1.406 & (0.773 to 2.020$)$ \\
\hline Subject 9 & 41 & -0.13 & 0.449 & 55.09 & $(37.86-71.61)$ & -0.133 & ( -0.571 to 0.309$)$ \\
\hline Subject 10 & 42 & 0.01 & 0.497 & 49.73 & $(32.80-66.68)$ & 0.007 & $(-0.431$ to 0.445$)$ \\
\hline Subject 11 & 44 & 0.28 & 0.391 & 39.13 & $(23.15-56.52)$ & 0.287 & $(-0.164$ to 0.731$)$ \\
\hline Subject 12 & 45 & 0.41 & 0.340 & 34.09 & (18.94-51.47) & 0.427 & $(-0.037$ to 0.880$)$ \\
\hline Subject 13 & 43 & 0.14 & 0.443 & 44.37 & $(27.90-61.62)$ & 0.147 & $(-0.296$ to 0.586$)$ \\
\hline Subject 14 & 54 & 1.64 & 0.058 & 5.82 & $(0.90-16.18)$ & 1.685 & (0.987 to 2.365$)$ \\
\hline Subject 15 & 53 & 1.50 & 0.073 & 7.39 & $(1.41-18.92)$ & 1.545 & (0.881 to 2.192$)$ \\
\hline Subject 16 & 36 & -0.81 & 0.213 & 78.66 & (62.29-90.90) & -0.832 & $(-1.335$ to -0.313$)$ \\
\hline Subject 17 & 50 & 1.09 & 0.142 & 14.28 & $(4.63-29.02)$ & 1.126 & (0.553 to 1.681 ) \\
\hline Subject 18 & 52 & 1.37 & 0.093 & 9.30 & $(2.16-21.98)$ & 1.406 & (0.773 to 2.020$)$ \\
\hline Subject 19 & 51 & 1.23 & 0.115 & 11.59 & $(3.21-25.35)$ & 1.266 & (0.664 to 1.850$)$ \\
\hline Subject 20 & 49 & 0.96 & 0.174 & 17.40 & $(6.48-33.00)$ & 0.986 & (0.440 to 1.515$)$ \\
\hline
\end{tabular}

\section{References}

Andrich, D. (1978). A rating formulation for ordered response categories. Psychometrika, 43, 357-374.

Atzeni, T. (2009). Statistiques appliquées aux études de cas unique: méthodes usuelles et alternatives. Revue neuropsychologie, article méthodologique, 1(4), 343-351.

Beidas, H., Khateb, A., \& Breznitz, Z. (2013). The cognitive profile of adult dyslexics and its relation to their reading abilities. Reading and Writing, 26(9), $1487-1515$.

Bishop, D. V. M., \& Snowling, M. J. (2004). Developmental dyslexia and specific language impairment: Same or different? Psychological Bulletin, 130(6), 858886.

Bjornsdottir, G., Halldorsson, J. G., Steinberg, S., Ingunn Hansdottir, I., Kristjansson, K., Stefansson, H., et al. (2013). The Adult Reading History Questionnaire (ARHQ) in Icelandic: Psychometric properties and factor structure. Journal of Learning Disabilities, 47(6), 532-542.

Boets, B., Op De Beeck, H. P., Vandermosten, M., Scott, S. K., Gillebert, C. R., Mantini, D., et al. (2013). Intact but less accessible phonetic representation in adults with dyslexia. Science, 342, 1251-1254.

Bruck, M. (1990). Word-recognition skills of adults with childhood diagnoses of dyslexia. Developmental Psychology, 26(3), 439-454.

Bruck, M. (1992). Persistence of dyslexics' phonological awareness deficits. Developmental Psychology, 28, 874-886.

Corkett, J. K., \& Parrila, R. (2008). Use of context in the word recognition process by adults with a significant history of reading difficulties. Annals of Dyslexia, 58(2), 139-161.

Crawford, J. R., Garthwaite, P. H., \& Porter, S. (2010). Point and interval estimates of effect sizes for the case-controls design in neuropsychology: Rationale, methods, implementations, and proposed reporting standards. Cognitive Neuropsychology, 27(3), 245-260.

Crawford, J. R., \& Howell, D. C. (1998). Comparing an individual's test score against norms derived from small samples. The Clinical Neuropsychologist, 12 , $482-486$

Crawford, J. R., \& Garthwaite, P. H. (2007). Comparison of a single case to a control or normative sample in neuropsychology: Development of a Bayesian approach. Cognitive Neuropsychology, 24, 343-372.

Deacon, S. H., Cook, K., \& Parrila, R. (2012). Identifying high-functioning dyslexics: Is self-report of early reading problems enough? Annals of Dyslexia, 62(2), $120-134$

Dunn, L. M., Thériault-Whalen, C. M., \& Dunn, L. M. (1993). Echelles de vocabulaire en image Peabody. Adaptation française du Peabody Picture Vocabulary Test-Revised. Psycan Toronto.

Dunn, M., \& Dunn, L. M. (1981). Peabody picture vocabulary test - Revised. Circle Pines, MN: AGS. 
Elbro, C. (2010). Dyslexia as disability or handicap: When does vocabulary matter? Journal of Learning Disabilities, 43(5), 469-478.

Elbro, C., \& Arnbak, E. (1996). The role of morpheme recognition and morphological awareness in dyslexia. Annals of Dyslexia, 46, 209-240.

Elbro, C., Nielsen, I., \& Petersen, D. K. (1994). Dyslexia in adults: Evidence for deficits in non-word reading and in the phonological representation of lexical items. Annals of Dyslexia, 44, 205-226.

Freitas, S., Prieto, G., Simões, M. R., \& Santana, I. (2014). Psychometric properties of the Montreal Cognitive Assessment (MoCA): An analysis using the Rasch model. The Clinical Neuropsychologist, 28(1), 65-83.

Gough, P. B., \& Tunmer, W. E. (1986). Decoding, reading, and reading disability. Remedial and Special Education, 7, 6-10.

Guo, Y., Roehrig, A. D., \& Williams, R. S. (2011). The relation of morphological awareness and syntactic awareness to adults' reading comprehension: Is vocabulary knowledge a mediating variable? Journal of Literacy Research: A Publication of the Literacy Research Association, 43(2), 159-183.

Gutman, R., DeDe, G., Michad, J., Liu, J., \& Caplan, D. (2010). Rasch models of aphasic performance on syntactic comprehension tests. Cognitive Neuropsychology, 27(3), 230-244.

Hatcher, J., Snowling, M. J., \& Griffiths, Y. M. (2002). Cognitive assessment of dyslexic students in higher education. The British Journal of Educational Psychology, 72, 119-133 Pt 1.

Helenius, P., Salmelin, R., Service, E., \& Connolly, J. F. (1999). Semantic cortical activation in dyslexic readers. Journal of Cognitive Neuroscience, 11(5), 535550.

Hulme, C., \& Snowling, M. J. (1992). Deficits in output phonology: An explanation of reading failure? Cognitive Neuropsychology, 9, 47-72.

Jones, M. W., Branigan, H. P., Parra, M. a., \& Logie, R. H. (2013). Cross-modal binding in developmental dyslexia. Journal of Experimental Psychology Learning Memory, and Cognition, 39(6), 1807-1822.

Kaplan, E., Goodglass, H., \& Weintraub, S. (1983). The Boston Naming Test. Philadelphia, PA: Lea \& Febiger.

Kirby, J. R., Silvestri, R., Allingham, B. H., Parrila, R., \& La Fave, C. B. (2008). Learning strategies and study approaches of postsecondary students with dyslexia. Journal of Learning Disabilities, 41, 85-96.

Lefavrais, P. (1967). Test de l'Alouette (2éme ed.). Paris: Editions du Centre de Psychologie Appliquée.

Lefavrais, P. (2005). Test de l'Alouette (ré étalonné en 2005). Paris: Les Editions du Centre de Psychologie Appliquée (ECPA).

Lefly, D. L., \& Pennington, B. F. (1991). Spelling errors and reading fluency in compensated adult dyslexics. Annals of Dyslexia, 41(1), 141-162.

Lefly, D. L., \& Pennington, B. F. (2000). Reliability and validity of the Adult Reading History Questionnaire. Journal of Learning Disabilities, $33,286-296$.

Leong, C. K. (1999). Phonological and morphological processing in adult students with learning/reading disabilities. Journal of Learning Disabilities, 32(3), 224-238.

Lesaux, N. K., Pearson, M. R., \& Siegel, L. S. (2006). The effects of timed and untimed testing conditions on the reading comprehension performance of adults with reading disabilities. Reading and Writing, 19, 21-48.

Linacre, J. M. (2013). Winsteps ${ }^{\circledR}$ Rasch measurement (Version 3.80.1) [Computer software]. Chicago, from PSYCH 101 at ASU.

Lum, J. A. G., Ullman, M. T., \& Conti-Ramsden, G. (2013). Procedural learning is impaired in dyslexia: Evidence from a meta-analysis of serial reaction time studies. Research in Developmental Disabilities, 34(10), 3460-3476.

Martin, J., Colé, P., Leuwers, C., Casalis, S., Zorman, M., \& Sprenger-Charolles, L. (2010). Reading in French-speaking adults with dyslexia. Annals of Dyslexia, $60(2), 238-264$

Martin, J., Frauenfelder, U. H., \& Colé, P. (2013). Morphological awareness in university students with dyslexia. Applied Psycholinguistics, 1-21.

Martinez Perez, T., Majerus, S., \& Poncelet, M. (2013). Impaired short-term memory for order in adults with dyslexia. Research in Developmental Disabilities, 34(7), 2211-2223.

Miller-Shaul, S. (2005). The characteristics of young and adult dyslexics readers on reading and reading related cognitive tasks as compared to normal readers. Dyslexia (Chichester, England), 11(2), 132-151.

Nagy, W., \& Herman, P. A. (1987). Breadth and depth of vocabulary knowledge: Implications for acquisition and instruction. In M. McKeown \& M. Curtis (Eds.), The nature of vocabulary acquisition (pp. 19-59). Hillsdale, NJ: Lawrence Erlbaum.

Nation, K., \& Snowling, M. (1998). Semantic processing and the development of word recognition skills: Evidence from children with reading comprehension difficulties. Journal of Memory and Language, 39, 85-101.

O'Brien, B. A., Orden, G. C., \& Pennington, B. F. (2013). Do dyslexics misread a ROWS for a ROSE? Reading and Writing, 26(3), 381-402.

Ouellette, G. P. (2006). What's meaning got to do with it: The role of vocabulary in word reading and reading comprehension. Journal of Educational Psychology, 98(3), 554-566.

Ouellette, G., \& Beers, A. (2010). A not-so-simple view of reading: How oral vocabulary and visual-word recognition complicate the story. Reading and Writing, 23(2), 189-208.

Ouellette, G., \& Shaw, E. (2014). Oral vocabulary and reading comprehension: An intricate affair. L'Année Psychologique, 114(04), 623-645.

Parrila, R., Georgiou, G., \& Corkett, J. (2007). University students with a significant history of reading difficulties: What is and is not compensated? Exceptionality Education Canada, 17(2), 195-220.

Paulesu, E., Démonet, J. F., Fazio, F., McCrory, E., Chanoine, V., Brunswick, N., et al. (2001). Dyslexia: Cultural diversity and biological unity. Science, 291, 2165-2167.

Quémart, P., \& Casalis, S. (2015). Visual processing of derivational morphology in children with developmental dyslexia: Insights from masked priming. Applied Psycholinguistics, 36, 345-376.

Ramus, F., \& Szenkovits, G. (2008). What phonological deficit? The Quarterly Journal of Experimental Psychology, 61(1), $129-141$.

Ramus, F., Rosen, S., Dakin, S. C., Day, B. L., Castellote, J. M., White, S., et al. (2003). Theories of developmental dyslexia: Insights from a multiple case study of dyslexic adults. Brain, 126(4), 841-865.

Ransby, M. J., \& Swanson, H. L. (2003). Reading comprehension skills of young adults with childhood diagnoses of dyslexia. Journal of Learning Disabilities, $36(6), 538-555$.

Rasch, G. (1960 [1980]). Probabilistic models for some intelligence and attainment tests. Copenhagen: Danmarks Paedagogiske Institute (Reprinted by University of Chicago, 1980).

Raven, J. C., Court, J. H., \& Raven, J. (1995). Manual for Raven's progressive matrices and vocabulary scales. Section 1: General overviews. Oxford: Oxford Psychologists Press.

Rey, A., Ziegler, J. C., \& Jacobs, A. M. (2000). Graphemes are perceptual reading units. Cognition, 75(1), B1-B12.

Richlan, F., Kronbichler, M., \& Wimmer, H. (2011). Meta-analyzing brain dysfunctions in dyslexic children and adults. NeuroImage, 56(3), $1735-1742$.

Rose, T. L., \& Rouhani, P. (2012). Influence of verbal working memory depends on vocabulary: Oral reading fluency in adolescents with dyslexia. Mind Brain, and Education, 6(1), 1-9.

Rüsseler, J., Becker, P., Johannes, S., \& Münte, T. F. (2007). Semantic, syntactic, and phonological processing of written words in adult developmental dyslexic readers: An event-related brain potential study. BMC Neuroscience, 8, 52.

Share, D. L. (2004). Orthographic learning at a glance: On the time course and developmental onset of self-teaching. Journal of Experimental Child Psychology, 87, 267-298.

Siegel, L. S., Share, D., \& Geva, E. (1995). Evidence for superior orthographic skills in dyslexics. Psychological Science, 6(4), $250-254$.

Snowling, M. (2000). Dyslexia (2nd ed.). Oxford: Blackwell.

Snowling, M. J., Nation, K., Moxham, P., Gallagher, A., \& Frith, U. (1997). Phonological processing skills of dyslexic students in higher education: A preliminary report. Journal of Research in Reading, 20, 31-41.

Sprenger-Charolles, L., \& Colé, P. (2013). Lecture et dyslexie: Approche cognitive. Paris: Dunod.

Sprenger-Charolles, L., Colé, P., Béchennec, D., \& Kipffer-Piquard, a. (2005). French normative data on reading and related skills from EVALEC, a new computerized battery of tests (end Grade 1, Grade 2, Grade 3, and Grade 4). Revue Européenne de Psychologie Appliquée/European Review of Applied Psychology, 55(3), 157-186. 
Swanson, H. L. (2012). Adults with reading disabilities: Converting a meta-analysis to practice. Journal of Learning Disabilities, 45(1), 17-30.

Swanson, H. L., \& Hsieh, C. J. (2009). Reading disabilities in adults: A selective meta-analysis of the literature. Review of Educational Research, 79(4), 13621390.

Trainin, G., \& Swanson, H. L. (2005). Achievement of college students with learning disabilities. Learning Disability Quarterly, 28(4), 261-272.

Tunmer, W. E., \& Chapman, J. W. (2012). The simple view of reading redux: Vocabulary knowledge and the independent components hypothesis. Journal of Learning Disabilities, 45(5), 453-466.

Vellutino, F. R., Scanlon, D. M., \& Spearing, D. (1995). Semantic and phonological coding in poor and normal readers. Journal of Experimental Child Psychology, 59, 76-123.

Vukovic, R. K., Wilson, A. M., \& Nash, K. K. (2004). Naming speed deficits in adults with reading disabilities: A test of the double-deficit hypothesis. Journal of Learning Disabilities, 37(5), 440-450.

Warmington, M., Stothard, S. E., \& Snowling, M. J. (2013). Assessing dyslexia in higher education: The York adult assessment battery-revised. Journal of Research in Special Educational Needs, 13(1), 48-56.

Wechsler, D. (1997). Wechsler adult intelligence scale (3rd ed.). San Antonio, TX: The Psychological Corporation.

Wilson, M. A., \& Lesaux, N. K. (2001). Persistence of phonological processing deficits in college students with dyslexia who have age-appropriate reading skills. Journal of Learning Disabilities, 34(5), 394-400.

Wiseheart, R., Altmann, L. J. P., Park, H., \& Lombardino, L. J. (2009). Sentence comprehension in young adults with developmental dyslexia. Annals of Dyslexia, 59(2), 151-167.

Wright, B. D., \& Douglas, G. A. (1986). The rating scale model for objective measurement. Research Memorandum 35. MESA Psychometric laboratory Dept of Education University of Chicago.

Ziegler, J. C., Jacobs, A. M., \& Stone, G. O. (1996). Statistical analysis of the bidirectional inconsistency of spelling and sound in French. Behavior Research Methods Instruments E' Computers, 28, 504-515. 